\title{
MicroRNA-106a regulates phosphatase and tensin homologue expression and promotes the proliferation and invasion of ovarian cancer cells
}

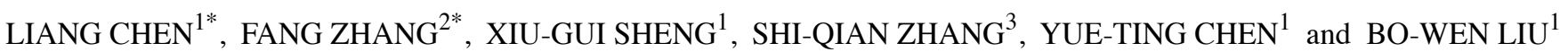 \\ ${ }^{1}$ Department of Gynecological Oncology, Shandong Cancer Hospital affiliated to Shandong University, \\ Shandong Academy of Medical Sciences, Jinan, Shandong 250117; ${ }^{2}$ Department of Radiology, Provincial \\ Hospital affiliated to Shandong University, Jinan, Shandong $250021 ;{ }^{3}$ Department of Obstetrics and \\ Gynecology, Qilu Hospital of Shandong University, Jinan, Shandong 250012, P.R. China
}

Received March 5, 2016; Accepted April 19, 2016

DOI: $10.3892 / o r .2016 .5010$

\begin{abstract}
Ovarian cancer is a leading cause of malignant gynecological tumor-related mortality among women. The treatment of ovarian cancer patients continues to be challenging. MicroRNA-106a (miR-106a) is widely expressed in diverse human tumors. In the present study, we investigated the biological and pathological roles of miR-106a in ovarian cancers. We found that miR-106a expression was significantly increased in primary ovarian cancer tissues and ovarian cancer cells compared with the level in normal tissues. Ectopic expression of an miR-106a inhibitor attenuated ovarian cancer cell proliferation and invasion. miR-106a promoted the growth and invasion of SKOV3 cells by targeting phosphatase and tensin homolog (PTEN). Furthermore, the present study revealed that IL-6 inhibited miR-106a expression by activating STAT3. Tocilizumab, a humanized anti-human IL-6R antibody, that competitively inhibits IL-6/IL-6R signaling, did not inhibit the proliferation and invasion of SKOV 3 cells. In conclusion, our studies revealed that miR-106a was significantly increased in the ovarian cancer tissues and cell lines. Downregulation of the expression of miR-106a inhibited cell growth and metastasis of ovarian cancer cells. Together, the present study suggests that miR-106a acts as an oncogene in ovarian cancers.
\end{abstract}

Correspondence to: Dr Xiu-Gui Sheng, Department of Gynecological Oncology, Shandong Cancer Hospital affiliated to Shandong University, Shandong Academy of Medical Sciences, 107 Jiyan Road, Jinan, Shandong 250117, P.R. China

E-mail: 155338644@qq.com

*Contributed equally

Key words: miR-106, ovarian cancer, invasion, proliferation

\section{Introduction}

Ovarian cancer is the second leading gynecological malignancy after cervical cancer. However, it is the most lethal gynecological malignancy, accounting for more deaths than endometrial and cervical cancers combined (1). Ovarian cancer is typically asymptomatic during the early stages, and most ovarian cancers are diagnosed at an advanced III or IV stage due to its deep pelvic location, multiple morphologies and characteristic genetic factors (2). The current standard of care includes surgical cytoreduction and platinum-based chemotherapy. Although cytoreductive surgery with chemotherapy can significantly prolong patient survival, most cancers eventually relapse and metastasize, becoming resistant and refractory to standard chemotherapy; the 5-year survival rate is $\sim 30 \%$ (3).

Growing evidence suggests that microRNAs (miRNAs) play an important role in tumor development, progression and metastasis and may offer a promising therapeutic strategy to improve the management of cancer patients. miRNAs are a class of small non-coding RNAs (18-22 nt in length) which regulate the expression of target genes by binding to the 3'-untranslated regions (3'-UTRs) resulting in the degradation of mRNAs or the translational inhibition of functional proteins (4). Emerging evidence strongly suggests the critical roles of miRNAs in the pathogenesis of ovarian cancer, including miR-106a. To date, miR-106a has been found to be upregulated or downregulated in many types of cancers, such as renal carcinoma (5), colon cancer (6), esophageal carcinoma (7), gastric (8) and lung cancer (9). However, the mechanism of miR-106a in ovarian cancer is not clear, thus, we aimed to reveal the role of miR-106a in ovarian cancer.

Recent convincing data support the involvement of the inflammatory stromal microenvironment, caused by overexpression of cytokines or chemokines, in promoting ovarian tumorigenesis, cancer progression and resistance to chemotherapies (10). Among the cytokines reported to date, interleukin-6 (IL-6) is one of the pivotal immunoregulatory cytokines present in the ovarian cancer microenvironment; it induces several pathways leading to tumor proliferation, 
angiogenesis and chemoresistance (11). Higher serum and ascites levels of IL-6 have been found in patients with ovarian cancer than levels in patients with other malignancies, and levels have been shown to correlate with the extent of disease and poor clinical outcome (12-14). Tocilizumab is a humanized anti-human IL-6R antibody and binds to the IL-6binding site of human IL-6R. It is known to competitively inhibit IL-6/IL-6R signaling and completely neutralizes IL-6 activities $(15,16)$. A series of clinical studies has successfully shown that the suppression of IL-6/IL-6R signaling by tocilizumab is therapeutically effective in alleviating Castleman's disease and rheumatoid arthritis $(17,18)$.

Hence, the present study was aimed to identify the role of miR-106a in ovarian cancer. miR-106a expression was analyzed in ovarian cancer tissues and cell lines. After that, we investigated the effects of miR-106a and tocilizumab on ovarian cancer cell proliferation, migration and invasion and further discuss the mechanisms of action of miR-106a by identifying its potential target gene.

\section{Materials and methods}

Antibodies and reagents. The antibodies for STAT3, and phospho-STAT3 were purchased from Abcam (Shanghai, China). The antibodies for phosphatase and tensin homolog (PTEN), N-cadherin, E-cadherin, SOCS6, vimentin and $\alpha$-tubulin were purchased from Proteintech (Wuhan, China). RIPA lysis buffer was purchased from CW Biotech (Beijing, China). Tocilizumab was purchased from Chugai Pharmaceutical (Shizuoka, Japan).

Clinical sample collection. Paired ovarian cancer tissues and normal contralateral ovary tissues were obtained from 15 patients who underwent primary surgical resection for ovarian cancer at Shandong Cancer Hospital affiliated to Shangdong University (Shandong, China). None of the patients had received pre-operative adjuvant therapy. These samples were snap-frozen in liquid nitrogen after resection. Prior patient consent and approval from the Ethics Committee of Shandong Cancer Hospital were obtained for the use of these clinical materials for research purposes.

Cell culture. SKOV3 and OVCAR3 cell lines were routinely maintained in Dulbecco's modified Eagle's medium (DMEM) (HyClone, Logan, UT, USA) supplemented with $10 \%$ fetal bovine serum (FBS) (CLARK), $100 \mathrm{U} / \mathrm{ml}$ penicillin sodium and $100 \mathrm{mg} / \mathrm{ml}$ streptomycin sulfate (Solarbio, Beijing, China) at $37^{\circ} \mathrm{C}$ in a humidified air atmosphere containing $5 \%$ $\mathrm{CO}_{2}$. Cells were used in the logarithmic growth phase.

Transfection of the miR-106a inhibitor. The inhibitor of miR-106a was purchased from RiboBio (Guangzhou, China). Transfection was performed when cells were grown to $80 \%$ confluency, using the NanoFectin Transfection Reagent (ExCell Biology, Shanghai, China) according to the manufacturer's instructions.

$R N A$ isolation and quantitative real-time PCR. Total RNA and miRNA were isolated using the Ultrapure RNA kit (CWBio, Beijing, China) according to the manufacturer's protocol. cDNA was reverse transcribed from total RNA samples using the miRNA cDNA kit (CWBio). miR-106a expression was detected by quantitative real-time PCR (qRTPCR) using the miRNA real-time PCR assay kit. The small nuclear RNA U6 was used for normalization. The relative amount of miR-106a was calculated using the cycle threshold (CT) value as the relative miRNA level. Each sample was performed in triplicate. The miR-106a and U6 primers were synthesized by Genewiz (Beijing, China). The following primers were used: miR-106a-F, AAA AGT GCT TAC AGT GCA GGT AG; and human U6-F, CTC GCT TCG GCA GCA CA.

Western blotting. Cells were harvested and lysed in cold RIPA lysis buffer containing 1\% Halt Protease (CWBio) for $30 \mathrm{~min}$. The supernatant was collected after $10 \mathrm{~min}$ of centrifugation at $12,000 \mathrm{rpm}$; the protein concentration of which was measured using the bicinchoninic acid method, then denatured with sample loading buffer for $5 \mathrm{~min}$ at $95^{\circ} \mathrm{C}$ and stored at $-20^{\circ} \mathrm{C}$ for future use. Equal amounts of proteins were separated by $10 \%$ SDS-polyacrylamide gel electrophoresis and transferred onto polyvinylidene fluoride membranes. After blocking with 5\% skim milk for $1 \mathrm{~h}$, the membranes were incubated with primary antibodies overnight at $4^{\circ} \mathrm{C}$ followed by secondary antibodies for $1 \mathrm{~h}$ at room temperature. The bands were subsequently detected by an enhanced chemiluminescence system (EMD Millipore, Billerica, MA, USA) and analyzed by Quantity One software.

Proliferation, invasion and migration assays. The cells were cultured in a 6-well plate. When the cells were grown to $80 \%$ confluency, the cells were transfected with 160 pmol of miR-106a, negative control (NC) or treated with tocilizumab (Chugai Pharmaceutical, Shizuoka, Japan) $(10 \mu \mathrm{g} / \mathrm{ml})$ for $48 \mathrm{~h}$.

For the Cell Counting kit-8 (CCK-8) assay, the cells $(1,000 /$ well $)$ were seeded into a 96-well plate in $100 \mathrm{ml}$ complete DMEM supplemented with $10 \% \mathrm{FBS}$, and cell growth was monitored at indicated time points using the CCK-8 assay.

For the cell Matrigel Transwell invasion assays, 24-well Transwell containing polycarbonate filters with $8-\mathrm{mm}$ pores (Corning Costar, Corning, NY, USA) and the inserts were precoated with $50 \mu \mathrm{l}$ Matrigel matrix (dilution at 1:3; BD Biosciences, Franklin Lakes, NJ, USA) according to the manufacturer's protocol, and $200 \mathrm{ml}$ cell suspension $\left(2 \times 10^{5}\right)$ obtained from the primary step in serum-free medium was placed into the upper chamber. The lower chamber was filled with $600 \mathrm{ml} 10 \%$ FBS-DMEM. The plates were subsequently incubated for $24 \mathrm{~h}$ under normal conditions. The cells, which had invaded the lower surface of the membrane, were fixed and stained with $0.1 \%$ crystal violet, The number of invading and migrating cells was calculated using a microscope at a magnification of x 200 in 5 random fields. Three independent experiments were performed.

For the wound-healing assay, the cells obtained from primary step one were seeded in a 6 -well plate. When the cells grew to a confluency of $90-95 \%$, the cell monolayer was scratched using a sterile $200-\mu 1$ pipette tip. After washing and removal of the detached cells, the plates were incu- 

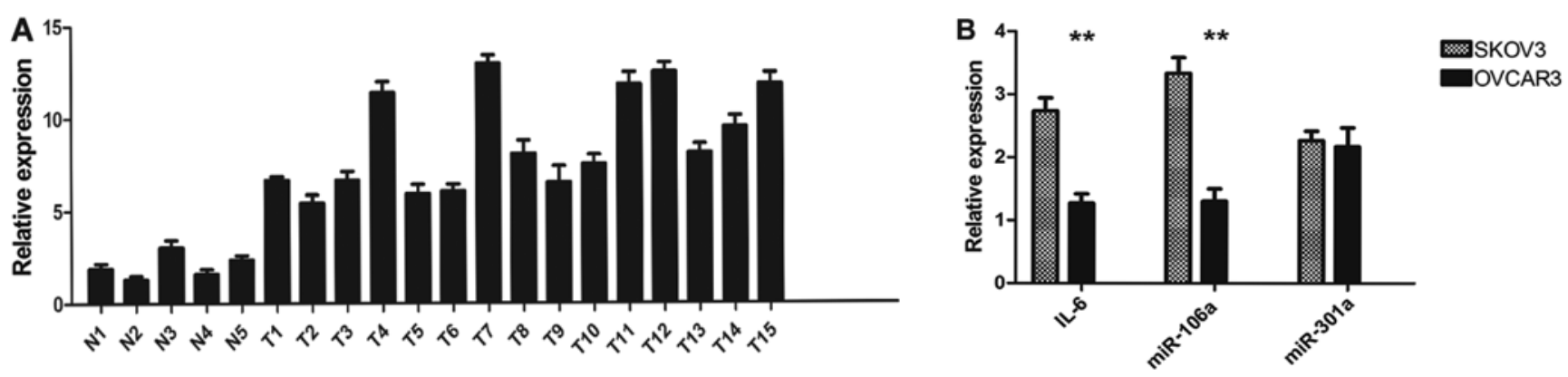

Figure 1. Relative expression levels of miR-106a in ovarian cancer tissues and cell lines. (A) The levels of IL-6, miR-106a and miR-301a were determined by qPCR and normalized to U6 snRNA in normal ovarian tissues and primary ovarian cancer samples. (B) The relative expression of IL-6, miR-106a and miR-301a in SKOV3 and OVCAR3 cell lines. ${ }^{* *} \mathrm{P}<0.01$.

A

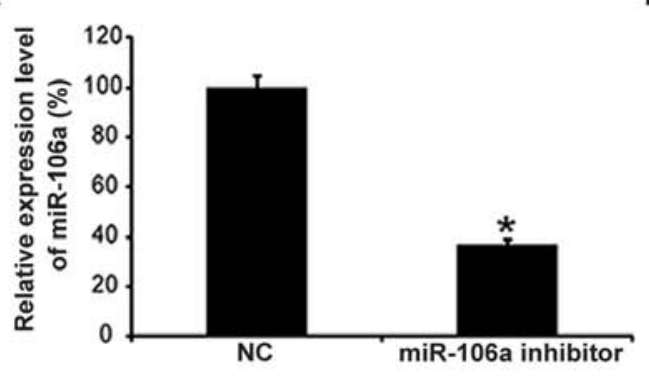

C
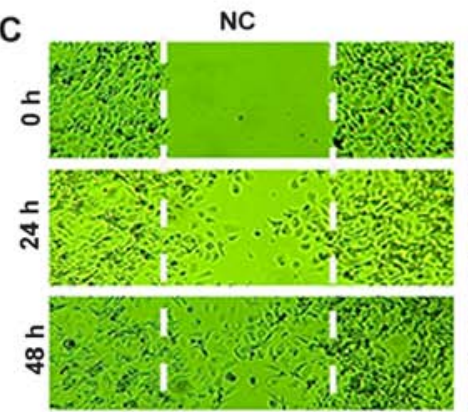

E

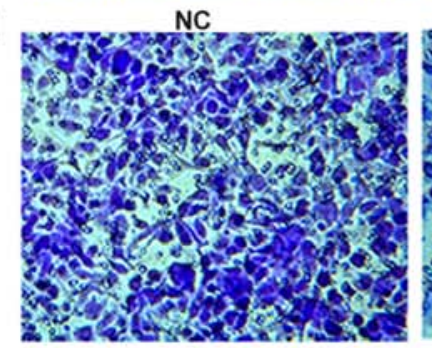

B

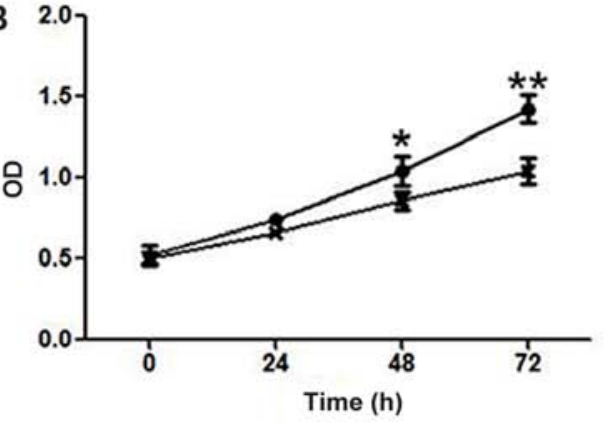

miR-106a inhibitor
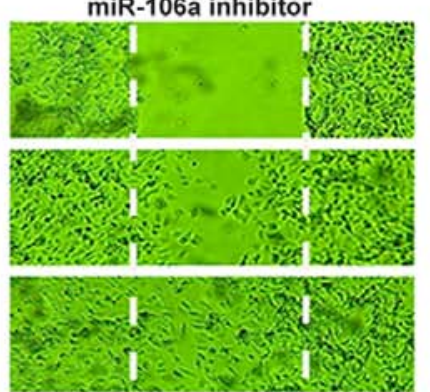

miR-106a inhibitor

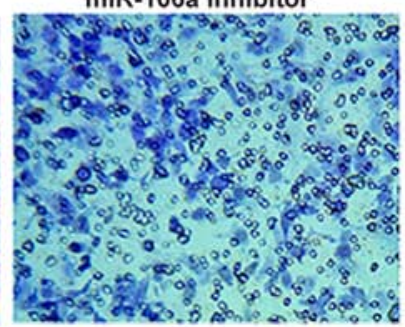

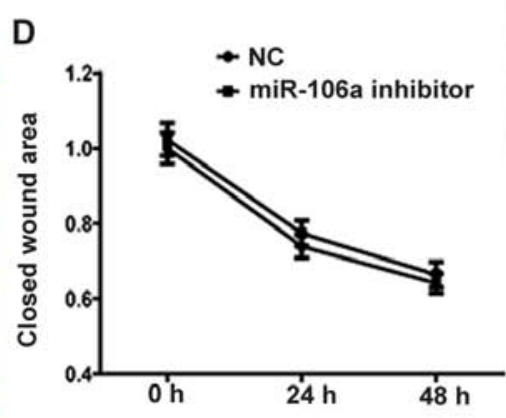

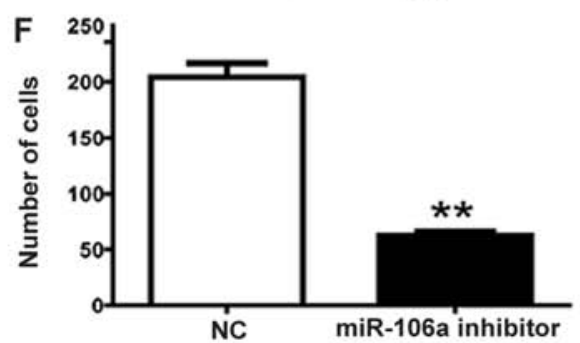

G

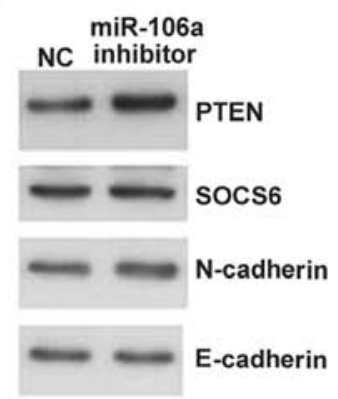

Vimentin

Tubulin

Figure 2. miR-106a inhibitor inhibits ovarian cancer cell proliferation and invasion. (A) The expression of miR-106a was determined by qPCR in ovarian cancer cells transfected with the miR-106a inhibitor. (B) The effect of miR-106a expression on cell proliferation was determined by CCK-8 assay. (C and D) The effect of miR-106a expression on the migration of ovarian cancer cells using a wound scratch healing assay. (E and F) The effect of miR-106a expression on the invasion of ovarian cancer cells using a Transwell invasion assay. (G) Levels of putative proteins which may be target genes of miR-106a in the cells were determined by western blotting; ${ }^{*} \mathrm{P}<0.05,{ }^{* *} \mathrm{P}<0.01$.

bated at $37^{\circ} \mathrm{C}$ with $\mathrm{FBS}$-free DMEM and the wounds were photographed every $24 \mathrm{~h}$. At least 5 different wounds were performed, and the experiments were independently repeated 3 times.

Statistical analysis. Statistical testing was conducted with the assistance of SPSS 17.0 software. All data are expressed as means \pm SD. Student's t-test and one-way analysis of variance (ANOVA) were used to analyze data. Results were considered significant at a P-value $<0.05$.

\section{Results}

miR-106a is upregulated in ovarian cancer samples and cell lines. In the present study, the levels of miR-106a were measured by quantitative real-time PCR in normal ovarian 
A

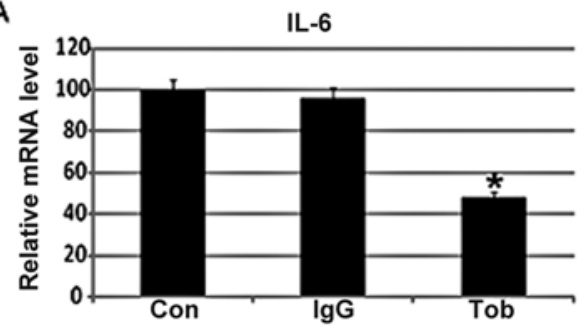

C

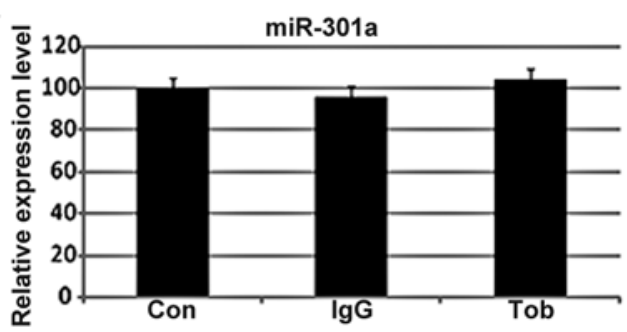

E

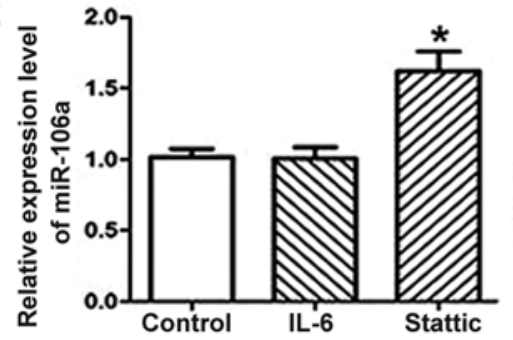

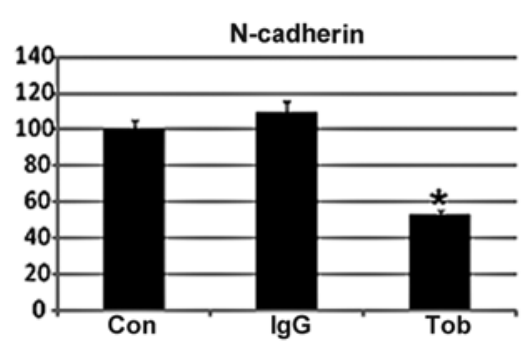

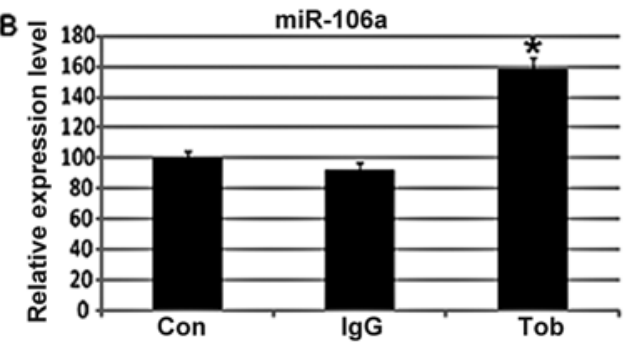

D
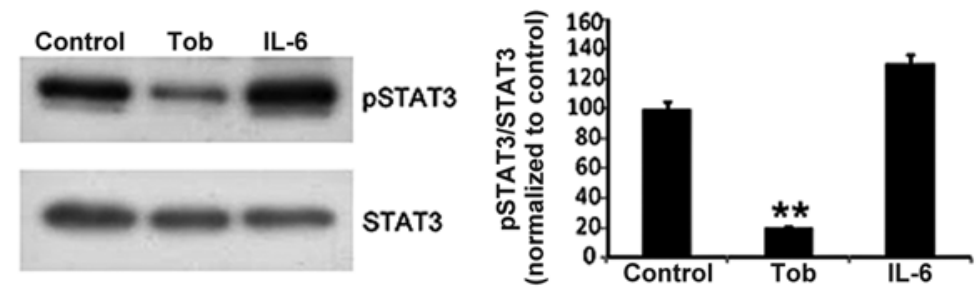

$\mathbf{F}$

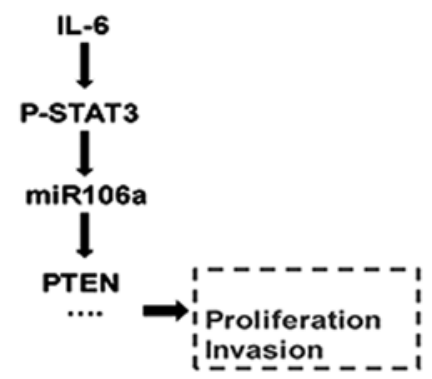

Figure 3. IL-6 inhibits miR-106a expression by activating STAT3. (A) The mRNA expression level of IL-6 and its downstream target N-cadherin was determined by qPCR after ovarian cancer cells were treated with tocilizumab (Tob) and IgG. (B) The expression level of miR-106a was determined after ovarian cancer cells were treated with Tob and IgG. (C) The expression level of miR301a was determined after ovarian cancer cells were treated with Tob and IgG. (D) The phosphoryation level of STAT3 was examined by western blotting after ovarian cancer cells were treated with Tob and IL-6. (E) The expression level of miR-106a was determined after the ovarian cancer cells were treated with IL-6 and STAT3 inhibitor Stattic. (F) The possible molecular mechanisms in the regulation of the growth and invasion of SKOV3 cells by miR-106a; $\mathrm{P}<0.05,{ }^{* *} \mathrm{P}<0.01$.

tissues and primary ovarian cancer samples. As shown in Fig. 1A, we found that miR-106a expression was significantly increased in the primary ovarian cancer tissues compared with that noted in the normal tissues $(\mathrm{P}<0.05)$. In addition, miR-106a expression levels were high in two ovarian cancer cell lines compared with the level in the normal ovarian tissues (Fig. 1A). We used SKOV3 cells in the cell function assay, due to higher IL-6 and miR-106a expression levels (Fig. 1B). These findings suggest that upregulation of miR-106a may play a role in ovarian cancer development.

miR-106a inhibitor inhibits ovarian cancer cell proliferation and invasion. To investigate the potential biological function of miR-106a in ovarian cancer, we modulated the miR-106a expression by transfection with the miR-106a inhibitor. Using qPCR, we found that the expression of miR-106a was significantly decreased in the cells transfected with the miR-106a inhibitor compared with that noted in the control group (NC) (Fig. 2A; $\mathrm{P}<0.05)$. In order to observe the impact of miR-106a on the cell proliferation of SKOV3 cells, the proliferation rates of SKOV3 cells treated with miR-106a inhibitor were determined by CCK-8 assay. As shown in Fig. 2B, growth inhibition was noted when the cells were transfected with the miR-106a inhibitor. To test the effect of miR-106a on the motility of SKOV3 cells, in vitro migration and invasion assays were performed. We assessed the effect of miR-106b on the migratory capacity of SKOV3 cells using a wound-healing assay. As shown in Fig. 2C and D, the miR-106a inhibitor had no effect on SKOV3 cell migration. In contrast, miR-106a inhibitor transfection suppressed SKOV3 cell invasion as detected by the Matrigel invasion assay (Fig. 2E and F). These observations revealed that miR106a significantly promoted the proliferation and invasion of SKOV3 cells. To investigate the molecular mechanism by which miR-106a suppresses the growth and invasion of SKOV3 cells, we detected putative target genes of miR-106a by western blotting. Among the candidates, PTEN was found to be regulated by miR-106a (Fig. 2G). On the contrary, SOCS6, N-cadherin, E-cadherin and vimentin were not significantly affected upon miR-106a inhibitor transfection (Fig. 2G). These findings suggest that miR-106a may promote the growth and invasion of SKOV3 cells by upregulating PTEN.

miR-106a is regulated by IL-6 in SKOV3 cells. Furthermore, we investigated the signaling that triggers the upregulation of miR-106a. Interleukin-6 (IL-6) is one of the important immunoregulatory cytokines present in the ovarian cancer microenvironment (11); IL6-R expression is highly expressed in ovarian cancer tissues compared with levels in normal tissues or benign diseases, and the IL-6 receptor pathway is believed to be a new therapeutic target in ovarian cancer $(11,19)$. 

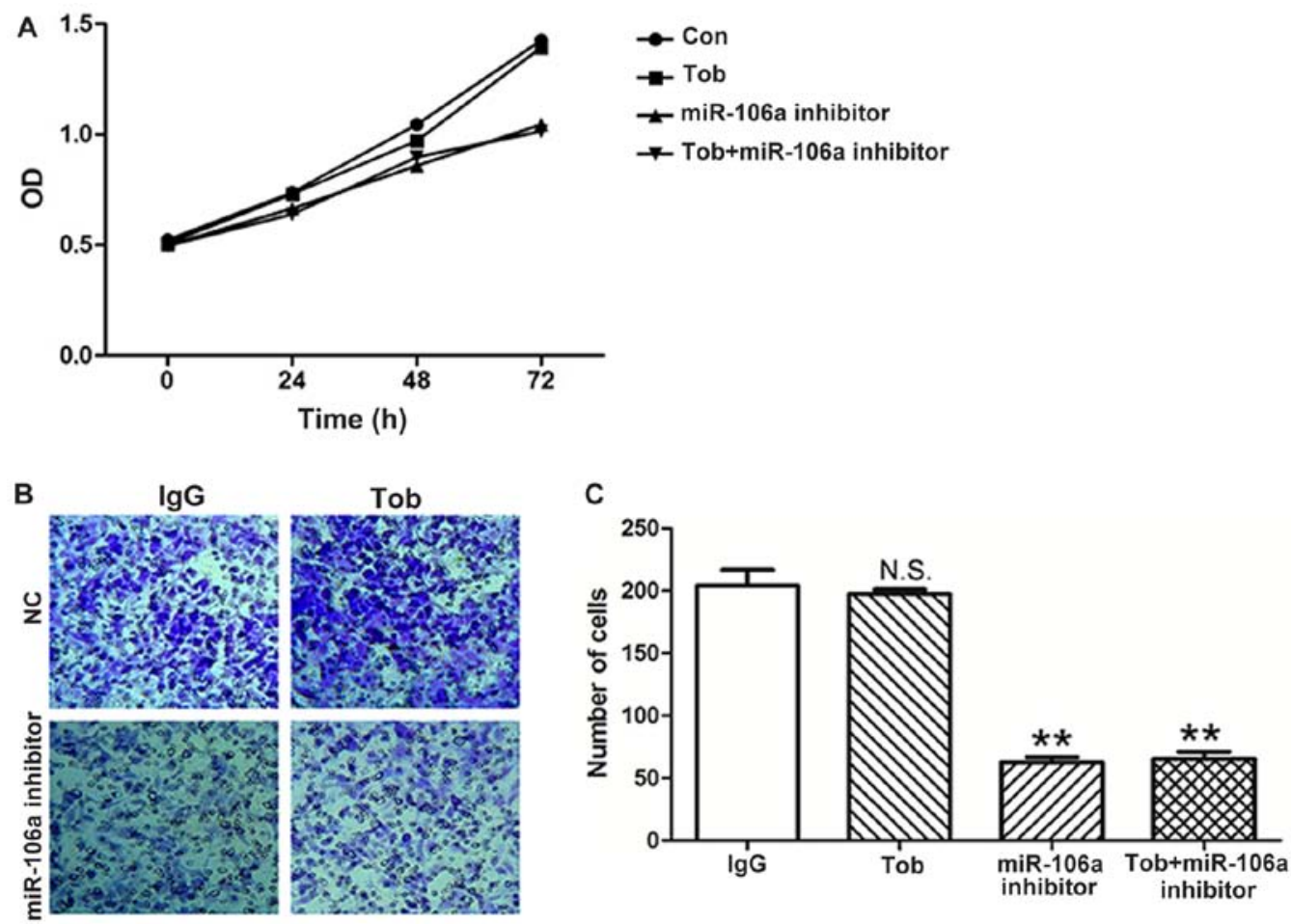

Figure 4. Tocilizumab (Tob) does not inhibit the proliferation and invasion of SKOV3 cells. (A) The effect of miR-106a expression on cell proliferation was determined by the CCK-8 assay. (B and C) The effect of miR-106A expression on invasion of ovarian cancer cells using Transwell invasion assay; ${ }^{* *} \mathrm{P}<0.01$. N.S., not significant.

Tocilizumab is a humanized anti-human IL-6R antibody and competitively inhibits IL-6/IL-6R signaling (19). As shown in Fig. 3A, tocilizumab decreased the mRNA level of IL-6 and its downstream target-N-cadherin herein. Notably, we found that tocilizumab significantly enhanced the expression of miR-106a (Fig. 3B), while the expression level of miR-301a was not affected (Fig. 3C). These findings suggest that IL-6 is a regulator of miR-106a in SKOV3 cells.

IL-6 inhibits miR-106a expression by activating STAT3. To investigate the molecular mechanism by which IL-6 suppresses miR-106a expression, we detected the activation level of STAT3, a target gene of IL-6. We found that tocilizumab significantly decreased the phosphoryation level of STAT3 (Fig. 3D). Furthermore, we found that STAT3 inhibitor Stattic increased the expression level of miR-106a (Fig. 3E). Thus, the present study indicated that IL- 6 is a regulator of miR-106a. IL-6 inhibits miR-106a expression by activating STAT3 in SKOV3 cells. Then, miR-106a may downregulate PTEN, and promote the growth and invasion of SKOV3 cells.

Tocilizumab does not inhibit the proliferation and invasion of SKOV3 cells. Tocilizumab has proven useful in treating IL-6-related cancers (20-25). We aimed to ascertain whether tocilizumab increases miR-106a expression, thus it may not be effective in ovarian cancers. Thus, we detected the impact of miR-106a on the cell proliferation and invasion of SKOV3 cells. As shown in Fig. 4A, tocilizumab did not inhibit the cell proliferation in SKOV3 cells. Co-treatment with the miR-106a inhibitor slowed down the cell proliferation. In addition, tocilizumab did not affect the invasion of the SKOV3 cells (Fig. 4B and C). The results suggest that tocilizumab may increase miR-106a expression, and the overexpression of miR-106a may impair the effect of tocilizumab on ovarian cancer cells.

\section{Discussion}

Ovarian cancer is a leading cause of malignant gynecological tumor-related deaths among women. The treatment of ovarian cancer patients continues to be challenging. MicroRNAs (miRNAs) have recently been described as important players in human cancer, and some are believed to be potential therapeutic targets. Expression of microRNAs is markedly deregulated in ovarian cancer, which strongly suggests that miRNAs are involved in the pathogenesis of ovarian cancer (26-42). In the present study, we identified the deregulation of miR-106a in ovarian cancer.

miR-106a is widely expressed in diverse human tumors, including gastric, non-small cell lung, pancreatic, colorectal and ovarian cancer $(6,8,9,43-53)$. Previous studies showed that miR-106a acts as a tumor suppressor or an oncogene in different cancers, depending on the different cellular context. In gastric cancer, expression of miR-106a was increased, and downregulation of the expression of miR-106a inhibited gastric cancer cell proliferation and caused apoptosis by targeting FAS (52). In non-small cell lung cancers, miR-106a inhibited the growth and metastasis of NSCLC cells by decreasing phosphatase and tensin homolog (PTEN) expression (9). In ovarian cancer, upregulation of miR-106a was found to be associated with paclitaxel and cisplatin resistance $(47,50)$.

In the present study, we investigated the biological and phthological roles of miR-106a in ovarian cancers. We 
found that miR-106a expression was significantly increased in primary ovarian cancer tissues and ovarian cancer cells compared with levels noted in normal tissues. Ectopic expression of the miR-106a inhibitor attenuated ovarian cancer cell line proliferation and invasion. These results demonstrated that miR-106a can promote ovarian cancer progression. A recent study reported that miR-106a promotes the growth and metastasis of non-small cell lung cancer by targeting PTEN (9). In line with this finding, we found that PTEN is also a direct target of miR-106a, and overexpression of miR-106a suppressed PTEN expression.

In addition, at the molecular level, the present study indicated that IL- 6 is a regulator of miR-106a. IL-6 inhibits miR-106a expression by activating STAT3. Interleukin-6 (IL-6) is one of the important immunoregulatory cytokines present in the ovarian cancer microenvironment (11); IL6-R expression is highly expressed in ovarian cancer tissues compared with that noted in normal tissues or benign diseases and the IL-6 receptor pathway is believed to be a new therapeutic target in ovarian cancer $(11,19)$. Tocilizumab is a humanized anti-human IL-6R antibody and binds to the IL-6-binding site of human IL-6R which competitively inhibits IL-6/IL-6R signaling (19). Tocilizumab has proven useful for treating IL-6-related cancers (20-25). The therapeutic potential of tocilizumab against ovarian cancer is still not well investigated. Our findings indicated that tocilizumab did not inhibit the proliferation and invasion of SKOV3 cells. This may be due to the upregulation of miR-106a which was triggered by IL- 6 activity inhibition. Thus, the miR-106a level must be considered before tocilizumab treatment.

In conclusion, the present study revealed that miR-106a was significantly increased in ovarian cancer tissues and cell lines. Downregulation of miR-106a expression inhibited cell growth and metastasis of ovarian cancer cells by increasing PTEN expression. IL-6 is a regulator of miR-106a by activating STAT3. Together, the present study suggests that miR-106a acts as an oncogene in ovarian cancers.

\section{Acknowledgements}

This study was supported by the Natural Science Foundation of Shandong Province (grant no. ZR2015YL047), Projects of Medical and Health Technology Development Program in Shandong Province (grant no. 2015WS0157) and the Science Foundation of Shandong Academy of Medical Sciences (grant no. 2014-50).

\section{References}

1. Siegel R, Naishadham D and Jemal A: Cancer statistics, 2013. CA Cancer J Clin 63: 11-30, 2013.

2. Gao L, Ye X, Ma RQ, Cheng HY, Han HJ, Cui H, Wei LH and Chang XH: Low programmed cell death 5 expression is a prognostic factor in ovarian cancer. Chin Med J 128: 1084-1090, 2015.

3. Kim MK, James J and Annunziata CM: Topotecan synergizes with CHEK1 (CHK1) inhibitor to induce apoptosis in ovarian cancer cells. BMC Cancer 15: 196, 2015.

4. Ma R, Jiang T and Kang X: Circulating microRNAs in cancer: Origin, function and application. J Exp Clin Cancer Res 31: 38, 2012.

5. Ma Y, Zhang H, He X, Song H, Qiang Y, Li Y, Gao J and Wang Z: miR-106a* inhibits the proliferation of renal carcinoma cells by targeting IRS-2. Tumour Biol 36: 8389-8398, 2015.
6. Yue B, Sun B, Liu C, Zhao S, Zhang D, Yu F and Yan D: Long non-coding RNA Fer-1-like protein 4 suppresses oncogenesis and exhibits prognostic value by associating with miR-106a-5p in colon cancer. Cancer Sci 106: 1323-1332, 2015.

7. Ma HL, Wen XP, Zhang XZ, Wang XL, Zhao DL, Che SM and Dang CX: miR-106a* inhibits the proliferation of esophageal carcinoma cells by targeting CDK2-associated Cullin 1 (CACUL1). Cell Mol Biol 61: 56-62, 2015.

8. Yuan R, Wang G, Zhi Q, Chen H, Han Y, Wang B, Kou Z, Hu H, Guo Z, Xue X, et al: Up-regulated circulating miR-106a by DNA methylation promised a potential diagnostic and prognostic marker for gastric cancer. Anticancer Agents Med Chem 15: 1, 2015.

9. Xie X, Liu HT, Mei J, Ding FB, Xiao HB, Hu FQ, Hu R and Wang MS: miR-106a promotes growth and metastasis of non-small cell lung cancer by targeting PTEN. Int J Clin Exp Pathol 8: 3827-3834, 2015.

10. Macciò $\mathrm{A}$ and Madeddu C: Inflammation and ovarian cancer. Cytokine 58: 133-147, 2012.

11. Dijkgraaf EM, Welters MJ, Nortier JW, van der Burg SH and Kroep JR: Interleukin-6/interleukin-6 receptor pathway as a new therapy target in epithelial ovarian cancer. Curr Pharm Des 18: 3816-3827, 2012

12. Plante M, Rubin SC, Wong GY, Federici MG, Finstad CL and Gastl GA: Interleukin-6 level in serum and ascites as a prognostic factor in patients with epithelial ovarian cancer. Cancer 73: 1882-1888, 1994.

13. Scambia G, Testa U, Benedetti Panici P, Foti E, Martucci R, Gadducci A, Perillo A, Facchini V, Peschle C and Mancuso S: Prognostic significance of interleukin 6 serum levels in patients with ovarian cancer. Br J Cancer 71: 354-356, 1995.

14. Duan Z, Foster R, Bell DA, Mahoney J, Wolak K, Vaidya A, Hampel C, Lee $\mathrm{H}$ and Seiden MV: Signal transducers and activators of transcription 3 pathway activation in drug-resistant ovarian cancer. Clin Cancer Res 12: 5055-5063, 2006.

15. Mihara M, Kasutani K, Okazaki M, Nakamura A, Kawai S, Sugimoto M, Matsumoto Y and Ohsugi Y: Tocilizumab inhibits signal transduction mediated by both mIL-6R and sIL-6R, but not by the receptors of other members of IL- 6 cytokine family. Int Immunopharmacol 5: 1731-1740, 2005.

16. Shinriki S, Jono H, Ota K, Ueda M, Kudo M, Ota T, Oike Y, Endo M, Ibusuki M, Hiraki A, et al: Humanized anti-interleukin-6 receptor antibody suppresses tumor angiogenesis and in vivo growth of human oral squamous cell carcinoma. Clin Cancer Res 15: 5426-5434, 2009.

17. Nishimoto N, Kanakura Y, Aozasa K, Johkoh T, Nakamura M, Nakano S, Nakano N, Ikeda Y, Sasaki T, Nishioka K, et al: Humanized anti-interleukin- 6 receptor antibody treatment of multicentric Castleman disease. Blood 106: 2627-2632, 2005.

18. Nishimoto N, Hashimoto J, Miyasaka N, Yamamoto K, Kawai S, Takeuchi T, Murata N, van der Heijde D and Kishimoto T: Study of active controlled monotherapy used for rheumatoid arthritis, an IL-6 inhibitor (SAMURAI): Evidence of clinical and radiographic benefit from an $\mathrm{x}$ ray reader-blinded randomised controlled trial of tocilizumab. Ann Rheum Dis 66: 1162-1167, 2007.

19. Isobe A, Sawada K, Kinose Y, Ohyagi-Hara C, Nakatsuka E, Makino H, Ogura T, Mizuno T, Suzuki N, Morii E, et al: Interleukin 6 receptor is an independent prognostic factor and a potential therapeutic target of ovarian cancer. PLoS One 10: e0118080, 2015.

20. Ando K, Takahashi F, Kato M, Kaneko N, Doi T, Ohe Y Koizumi F, Nishio K and Takahashi K: Tocilizumab, a proposed therapy for the cachexia of Interleukin6-expressing lung cancer. PLoS One 9: e102436, 2014.

21. Ando K, Takahashi F, Motojima S, Nakashima K, Kaneko N, Hoshi K and Takahashi K: Possible role for tocilizumab, an antiinterleukin- 6 receptor antibody, in treating cancer cachexia. J Clin Oncol 31: e69-e72, 2013.

22. Berti A, Boccalatte F, Sabbadini MG and Dagna L: Assessment of tocilizumab in the treatment of cancer cachexia. J Clin Oncol 31: 2970, 2013.

23. Hirata H, Tetsumoto S, Kijima T, Kida H, Kumagai T, Takahashi R, Otani Y, Inoue K, Kuhara H, Shimada K, et al: Favorable responses to tocilizumab in two patients with cancer-related cachexia. J Pain Symptom Manage 46: e9-e13, 2013.

24. Kim NH, Kim SK, Kim DS, Zhang D, Park JA, Yi H, Kim JS and Shin HC: Anti-proliferative action of IL-6R-targeted antibody tocilizumab for non-small cell lung cancer cells. Oncol Lett 9: 2283-2288, 2015. 
25. Yamagata K, Shimojo N, Ito H, Ijima J, Hasegawa S, Yanagawa T, Mizutani T and Bukawa H: Severe pulmonary suppuration with infection-induced systemic inflammatory response syndrome following tongue cancer surgery in a patient undergoing tocilizumab therapy for rheumatoid arthritis. Case Rep Dent 2014: 649086, 2014.

26. Calin GA and Croce CM: MicroRNA-cancer connection: The beginning of a new tale. Cancer Res 66: 7390-7394, 2006.

27. Chen W, Huang L, Hao C, Zeng W, Luo X, Li X, Zhou L, Jiang S, Chen Z and He Y: MicroRNA-155 promotes apoptosis in SKOV3, A2780, and primary cultured ovarian cancer cells. Tumour Biol: Jan 15, 2016 (Epub ahead of print).

28. Chen W, Zeng W, Li X, Xiong W, Zhang M, Huang Y, Zhou L and Jiang S: MicroRNA-509-3p increases the sensitivity of epithelial ovarian cancer cells to cisplatin-induced apoptosis. Pharmacogenomics 17: 187-197, 2016.

29. Fan JY, Yang Y, Xie JY, Lu YL, Shi K and Huang YQ MicroRNA-144 mediates metabolic shift in ovarian cancer cells by directly targeting Glut1. Tumour Biol 37: 6855-6860, 2016.

30. Fu X, Cui Y, Yang S, Xu Y and Zhang Z: MicroRNA-613 inhibited ovarian cancer cell proliferation and invasion by regulating KRAS. Tumour Biol 37: 6477-6483, 2016 (In Chinese).

31. Guo P, Peng D, Xiong $X$ and Zhang S: Expression of microRNA-100 and its correlation with drug resistance in human ovarian cancer SKOV3/DDP cells. Nan Fang Yi Ke Da Xue Xue Bao 35: 1624-1627, 2015 (In Chinese)

32. Langhe R: microRNA and ovarian cancer. Adv Exp Med Biol 889: 119-151, 2015 .

33. Liang H, Jiang Z, Xie G and Lu Y: Serum microRNA-145 as a novel biomarker in human ovarian cancer. Tumour Biol 36 : 5305-5313,2015.

34. Liu X and Li G: MicroRNA-133b inhibits proliferation and invasion of ovarian cancer cells through Akt and Erk1/2 inactivation by targeting epidermal growth factor receptor. Int J Clin Exp Pathol 8: 10605-10614, 2015.

35. Luo P, Fei J, Zhou J and Zhang W: microRNA-126 suppresses PAK4 expression in ovarian cancer SKOV3 cells. Oncol Lett 9: 2225-2229, 2015

36. Pal MK, Jaiswar SP, Dwivedi VN, Tripathi AK, Dwivedi A and Sankhwar P: MicroRNA: A new and promising potential biomarker for diagnosis and prognosis of ovarian cancer. Cancer Biol Med 12: 328-341, 2015.

37. Quitadamo A, Tian L, Hall B and Shi X: An integrated network of microRNA and gene expression in ovarian cancer. BMC Bioinformatics 16 (Suppl 5): S5, 2015

38. Shariati-Kohbanani M,Zare-Bidaki M,Taghavi MM, Taghipour Z, Shabanizadeh A, Kennedy D, Dahim H, Salahshoor MR, Jalili C and Kazemi Arababadi M: DNA Methylation and microRNA patterns are in association with the expression of BRCA1 in ovarian cancer. Cell Mol Biol 62: 16-23, 2016.
39. Sun KX, Jiao JW, Chen S, Liu BL and Zhao Y: MicroRNA-186 induces sensitivity of ovarian cancer cells to paclitaxel and cisplatin by targeting ABCB1. J Ovarian Res 8: 80, 2015.

40. Wang $\mathrm{ZH}$ and $\mathrm{Xu} \mathrm{CJ}$ : Research progress of microRNA in early detection of ovarian cancer. Chin Med J 128: 3363-3370, 2015.

41. Wu DD, Li XS, Meng XN, Yan J and Zong ZH: MicroRNA-873 mediates multidrug resistance in ovarian cancer cells by targeting ABCB1. Tumour Biol: Feb 5, 2016 (Epub ahead of print).

42. Ying HC, Xu HY, Lv J, Ying TS and Yang Q: MicroRNA signatures of platinum-resistance in ovarian cancer. Eur J Gynaecol Oncol 36: 16-20, 2015.

43. Catela Ivkovic T, Aralica G,Cacev T, Loncar B and Kapitanovic S: miR-106a overexpression and pRB downregulation in sporadic colorectal cancer. Exp Mol Pathol 94: 148-154, 2013.

44. Díaz R, Silva J, García JM, Lorenzo Y, García V, Peña C, Rodríguez R, Muñoz C, García F, Bonilla F, et al: Deregulated expression of miR-106a predicts survival in human colon cancer patients. Genes Chromosomes Cancer 47: 794-802, 2008

45. Fang Y, Shen H, Li H, Cao Y, Qin R, Long L, Zhu X, Xie C and $\mathrm{Xu}$ W: miR-106a confers cisplatin resistance by regulating PTEN/Akt pathway in gastric cancer cells. Acta Biochim Biophys Sin 45: 963-972, 2013.

46. Hou X, Zhang M and Qiao H: Diagnostic significance of miR-106a in gastric cancer. Int J Clin Exp Pathol 8: 13096-13101, 2015.

47. Huh JH, Kim TH, Kim K, Song JA, Jung YJ, Jeong JY, Lee MJ, Kim YK, Lee DH and An HJ: Dysregulation of miR-106a and miR-591 confers paclitaxel resistance to ovarian cancer. Br J Cancer 109: 452-461, 2013

48. Koga Y, Yamazaki N, Yamamoto Y, Yamamoto S, Saito N, Kakugawa Y, Otake Y, Matsumoto M and Matsumura Y: Fecal miR-106a is a useful marker for colorectal cancer patients with false-negative results in immunochemical fecal occult blood test. Cancer Epidemiol Biomarkers Prev 22: 1844-1852, 2013.

49. Li P, Xu Q, Zhang D, Li X, Han L, Lei J, Duan W, Ma Q, Wu Z and Wang Z: Upregulated miR-106a plays an oncogenic role in pancreatic cancer. FEBS Lett 588: 705-712, 2014.

50. Rao YM, Shi HR, Ji M and Chen CH: MiR-106a targets Mcl-1 to suppress cisplatin resistance of ovarian cancer A2780 cells. J Huazhong Univ Sci Technolog Med Sci 33: 567-572, 2013.

51. Schee K, Boye K, Abrahamsen TW, Fodstad $\varnothing$ and Flatmark K: Clinical relevance of microRNA miR-21, miR-31, miR-92a, miR-101, miR-106a and miR-145 in colorectal cancer. BMC Cancer 12: 505, 2012.

52. Wang Z, Liu M, Zhu H, Zhang W, He S, Hu C, Quan L, Bai J and $\mathrm{Xu}$ N: miR-106a is frequently upregulated in gastric cancer and inhibits the extrinsic apoptotic pathway by targeting FAS. Mol Carcinog 52: 634-646, 2013.

53. Zhang L, Meng L, Fan Z, Liu B, Pei Y and Zhao Z: Expression of plasma miR-106a in colorectal cancer and its clinical significance. Nan Fang Yi Ke Da Xue Xue Bao 34: 354-357, 2014 (In Chinese). 